\author{
И.О. Чугунова
}

\title{
ЦЕННОСТИ НАШЕГО ВЕКА ЧЕРЕЗ ПРИЗМУ ФИЛОСОФСКОЙ АНТРОПОЛОГИИ МАКСА ШЕЛЕРА
}

\begin{abstract}
Аннотация. Предметом данного исследования являются аксиологические проблемы человека и общества. Затрагиваются кризисные аспекты современного (постмодернистского) аксиологического этоса, интерпретируются ценностные "синдромы», связанные с экономикой сверхпотребления, тотальной информатизачией общества, формированием жестко-конкурентной среды. Автор ставит проблему различения ценностей-благ и псевдоценностей. Анализируется вопрос замещения истинных ценностей их суррогатами, описываются и интерпретируются соответствующие феномены. Акцентируется внимание на остро стоящей проблеме выхолащивания духовности, обезличивания человека. Рассматривается взаимосвязь ценностных проблем эпохи и иенностных проблем индивида. Исследование проведено в философрско-антропологическом русле, с опорой на ключевые положения теории М. Шелера, одного из основателей философской антропологии. Автором впервые предпринята попытка использования потенциала философской антропологии для анализа аксиологических феноменов. Исходя из шелеровского понимания природы человека, в статье продуктивно проанализирован ряд ченностных проблем человека и общества, сделан вывод о рисках, заложенных самой человеческой природой, и необходимости действовать им вопреки, о значимости душевных усилий.
\end{abstract}

Ключевые слова: аксиология, философская антропология, ченности, природа человека, ченностный этос, ценности-блага, псевдоценности, агатология, современное общество, постмодерн.

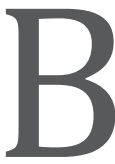

наше прагматическое время всё острее ощущается девальвация духовности. Потенциально многомерная реальность ценностей, способная открывать перед человеком новые горизонты и расширять пределы его бытия, в нынешних социокультурных условиях приобретает всё большую уплощенность. Духовность маргинализируется, выталкивается из границ массового сознания. Однако именно на этом фоне обостряется потребность человека мыслящего осознать сущностное значение духа для его носителя и объяснить патогенные процессы ценностного строя общества.

Сегодня мы наблюдаем очередную волну аксиологических исследований, однако в основной массе они носят прикладной характер, и этот процесс происходит в условиях методологического хаоса, касающегося самой теории ценностей. При этом аксиология пока так и не находит четкой локализации в общей структуре современной филосо- фии ${ }^{1}$. На наш взгляд, в восполнении данного методологического пробела значительную роль может сыграть установление связей между аксиологической дисциплиной и философской антропологией, в её классическом понимании.

Одним из основоположников и наиболее видных представителей философской антропологии является Макс Шелер. Он также является одним из пионеров аксиологии как отдельной дисциплины. Его теорию ценностей и по сей день, по прошествии века, считают образцовой и пока непревзойдённой по своей масштабности и концептуальной глубине 2 . И хотя философско-антропологические и

\footnotetext{
1 Шохин В.К. Аксиология // Новая философская энциклопедия: В 4-х тт. / Под ред. В.С. Стёпина. М.: Мысль, 2001. (URL: http://iph.ras.ru/page47086732.htm).

2 Чухина Л.А. Человек и его ценностный мир в феноменологической философии Макса Шелера // Шелер М. Избранные произведения / Под ред. А.В. Денежкина. М., 1994. С. 379-381.
} 
аксиологические прозрения этого мыслителя стали одной из заметных основ более позднего аксиологического дискурса (что мы наблюдаем, например, в работах В.Франкла), шелеровская теория заслуживает гораздо большего внимания, чем ей в действительности сегодня уделено, по крайней мере, в русскоязычной литературе. Философскоантропологические идеи Шелера сегодня не только не утратили своей актуальности: напротив, они потенциально востребованы там, где мы хотим предоставить аксиологии новую методологическую перспективу, а также найти более глубокий подход к размышлению о ценностных процессах современного общества.

Само понятие «ценность» Шелер раскрывает через анализ антропологических основ человеческой природы, и именно это придаёт его трактовке особую объемность. Ценность не рассматривается Шелером как прерогатива человека: прототипы аксиологических отношений с миром философ усматривает уже у животных. Хотя животный индивид не обладает ни мышлением, ни образными представлениями, он, тем не менее, чувственно воспринимает специфические интенции объектов окружающей среды - притяжения и отталкивания - и затем дифференцирует сопротивления этой среды именно по ценностным впечатлениям ${ }^{3}$. В этих наиболее простых формах аксиологического отношения к миру раскрывается объективный статус ценностей, их онтологичность: согласно теории Шелера, они существуют сами по себе и самообнаруживаются в чувственном, эмоциональном контакте животного индивида с миром (принцип эмоционального априори). Нас не должно удивлять сходство животного и человека - ведь последний является выходцем из природного мира. Здесь вопрос возникает в другом: в чём состоит антропологическое отличие человека от животных, если не в обладании ценностями и способности к ценностной ориентации в окружающем мире? Ведь неоспоримо и то, что высокоразвитый интеллект также не является критерием такого отличия: многократно доказывалось, что зачатки интеллекта имеются и у высших животных. Наличие у человека сознания также не является самоочевидным основанием для такого отличия. Ведь именно у животных и появляется та функция, которая впоследствии

3 Шелер М. Положение человека в космосе // Шелер М. Избранные произведения / Под ред. А.В. Денежкина. М., 1994. C. 143. даст начало сознанию: это re-flexio, способность к отражению сопротивления среды. Она появляется «в паре» с моторной функцией, в результате расщепления универсальной природной энергии ${ }^{4}$, как инструмент ориентации в окружающей среде, и характер этой ориентации - именно ценностный. Таким образом, становление человека происходит вовсе не благодаря линейному наращиванию интеллектуальной функции и способности к ценностному отражению мира, хотя всё это само по себе уже придает поведению пластичность и открывает возможность освобождения от жесткой инстинктивной программы. Ключевое антропологическое отличие человека от остального природного мира состоит в другом: в способе обхождения с ценностями, в дистанции по отношению к ним, в потенциальной не-встроенности в ценностный мир и определенной свободе в своих выборах и актах, что позволяет ему по своему творческому усмотрению конструировать собственную реальность, не тождественную биологической природе.

В этих антропологических свойствах раскрывается то, что мы обычно называем ёмким понятием «дух». Однако и понятие духа в шелеровской антропологии высвечивается новыми гранями. Дух, согласно теории Шелера, не обладает самостоятельной силой. Если природная энергия, животные влечения в человеке придают импульс и животворящую энергию его актам, то дух бессилен. Но его роль бесценна: он открывает путь этому импульсу, направляет и руководит, придаёт смысл и образ. Сам по себе лишенный силы, он способен говорить «нет» витальным порывам: тормозить, вытеснять или сублимировать животные влечения в духовные акты. Как пишет Шелер, такое обращение человека с действительностью «динамически прямо-таки перевернуто по сравнению с животным» ${ }^{5}$. И если ценностные предпочтения здорового животного так или иначе подчинены биологической логике, то человек по-другому, парадоксальным образом обходится с ценностями, выбирая, например, нужное в ущерб приятному, прекрасное в ущерб прагматичному. На это не способно ни одно другое существо.

Человек, по Шелеру, - «место» самообнаружения ценностей. Чем больше он вовлечен в ценностное постижение мира, тем больше бытийствующие

\footnotetext{
Там же. С. 136-138.

Там же. С. 154.
} 
в мире ценности открывают ему свою потаённость и глубину. В свою очередь, двигаясь вглубь онтологии ценностного мира, человек раздвигает границы бытия - как бытия собственного, так и бытия вообще. Именно в этом и видел Шелер высшее предназначение человека: в «животворении духа», придании мощи высшим духовным идеям, в обеспечении их воплощения ${ }^{6}$. И возможные пути реализации этого предназначения - безграничны: манящий горизонт идеального, вовлекая человека, отдаляется, открывая ему всё новый простор для свободы - творить мир и самого себя.

Шелер уже более века назад остро ощущал кризис европейской культуры. Он неоднократно указывал на то, что по мере развития современного общества человек всё больше отодвигается от самого себя и своей подлинной жизни. Философ писал о том, что социально-антропологический этос «фаустовского» типа с его культом научно-технического прогресса и прагматизма, с его односторонней научно-позитивистской картиной мира, опасен: упускается из внимания становление личности, духовное воспитание. Процесс развития общества, как указывает М. Шелер, односторонен и направлен «во вне», в то время как его должно сопровождать искусство «внутренней власти», ухода в себя, терпения, контакта с духовным, сущностным ${ }^{7}$.

Черты современного ценностного этоса указывают лишь на усугубление кризисных реалий. Примат ценностей экономического процветания и «слепого» технического прогресса образуют всё более ощутимый барьер между индивидом и его подлинным бытием. Прочно вошедшая в нашу жизнь сверхпотребительская идеология эксплуатирует энергию человеческих влечений - тех природных сил, которые, по Шелеру, даны человеку лишь как источник энергии - для «животворения» духа, освоения новых ценностных горизонтов бытия. Идолы современности направляют эту энергию в иное русло - на поиск чувственных удовольствий. Удовлетворение влечений, став на путь гедонизма и гипертрофируясь, превращается в источник примитивных наслаждений. Вместо возможной широты и творческого многообразия ценностной жизни мы всё чаще видим их узкие, косные невротические замещения. Стоит ли говорить, что спектр его вариантов в наше время продолжает расширяться. Так, шопо-

\footnotetext{
6 Там же. С. 175.

7 Малинкин А.Н. Философская социология Макса Шелера // Шелер М. Проблемы социологии знания. М., 2011. С. 271.
}

голизм в наш век перепроизводства материальных благ стал нормой; гэмблинг-зависимость является не более чем естественным атрибутом непомерно разросшейся индустрии развлечений. В этих явлениях задействован описанный Шелером механизм формирования удовлетворенности жизнью: если «интенция ценности» более высокого порядка не получила своего «исполнения» в жизни, если какойто крупный, важный для человека смысл, заданный этой высшей ценностью, так и остался нереализованным, как бы незамеченным, человек не чувствует себя удовлетворенным в центральной сфере жизни. Вследствие этого, говоря словами Шелера, «при неудовлетворенности в этих центральных слоях нашего бытия место полного удовлетворения [...] тотчас занимают «неудовлетворенные» безостановочные поиски ценностей наслаждения, [...] каждая из тысячи форм практического гедонизма всегда есть лишь знак «неудовлетворенности» высшими ценностями». Философ добавляет, что «уровень стремления к удовольствию находится в обратном отношении к глубине удовлетворения ценностью и ее местом в иерархии» ${ }^{8}$.

Гедонистические стремления в нашем обществе, давно принявшие массовый характер, могут объясняться, по крайней мере, в немалой степени, отсутствием центральной, стержневой ценностной удовлетворенности современного человека, при всем спектре возможных жизненных сценариев. Здесь уместно говорить о значительной и постоянно растущей «духовной бреши» в самой системе ценностей современного общества, неспособной напитывать духовными ориентирами подрастающие поколения, замещая эти ориентиры хаотичной россыпью псевдоценностей. Согласно шелеровской антропологии, человек, приходящий в этот мир, является носителем данных ему природой порывов, импульсов, энергии к жизни и росту, он так или иначе пытается определить для себя вектор реализации этой энергии и потенциально готов к духовному самораскрытию в соответствии с абсолютным миром ценностей. Но в существующем ценностном хаосе, вместо человека духовного, реализующего свою сущность и предназначение, появляется человек одномерный, придаток общества потребления.

Другим типичным следствием не реализовавшейся встречи индивида и мира истинных

8 Шелер М. Формализм в этике и материальная этика ценностей // Шелер М. Избранные произведения / Под ред. А.В. Денежкина. М., 1994. С. 316. 
ценностей, конгруэнтных потребностям его духовного начала, является синдром «самопредательства», когда выбор индивида, являющийся сугубо рационалистическим, диктуемый превалирующими ценностными идеалами общества, совершается не в пользу «зова» духа. Даже ощущая «притяжение» духовных ценностей, сегодняшний человек конформистски отвергает их, по крайней мере, как приоритетные. В психоаналитической традиции широко прорабатывается проблематика «ухода от себя», рационального подчинения своей жизни некоей социально одобряемой системе ценностей: вспомним хотя бы «тиранию долженствования», основанную на невротически облигатном следовании социальным образцам должного (К. Хорни) или феномен «бегства от свободы» (Э. Фромм).

Господствующую ныне систему ценностей, вслед за Г. Маркузе, можно без преувеличения назвать ценностной системой неототалитарного общества, с его «мягким», но неуклонным насилием над человеческой природой, с высокой степенью духовной депривации. Одномерность общественного сознания и современной «философии» масс, описанной Маркузе, выражается в уплощенной системе ценностей, лишенной тех духовных осей, вокруг которых и должно кристаллизоваться то высшее назначение человека, о котором писал Шелер. Причем, главная драма ценностной перестройки общества, согласно Маркузе, состоит в том, что духовные ценности не столько упраздняются, сколько встраиваются в утвердившийся порядок массового воспроизводства, становясь инструментом и товаром9.

Всё новые мрачные черты приобретает век информатизации - Интернета и глобальных социальных сетей, деформируя ценностные шаблоны нового поколения. Современные мыслители всё тревожнее отзываются о переменах, происходящих с человеком в информатизированном обществе, говоря уже не только о кризисе духовности, но и начавшемся процессе «самоампутации» человеческого духа ${ }^{10}$. Кажется невозможным, но у нас действительно появилось новое восприятие реальности, которое разрушает «монополию и приоритет мира видимого», материального бытия ${ }^{11}$. Мир вир-

\footnotetext{
9 Маркузе Г. Одномерный человек. М., 2011.

10 Маклюэн М., Фиоре К. Война и мир в глобальной деревHe. М., 2012. С. 7.

11 Там же. С. 12.
}

туального с присущим ему агрессивным натиском и всё более «реалистичной» действительностью формирует новый слой реальности, являющейся, по сути, завесой между человеком и истинным миром ценностей. Выхолащиваются ценности отношений, заменяемых виртуальными сетевыми суррогатами. Феномен «одиночества в сети» представляется здесь скорее здоровым человеческим переживанием, живой реакцией, в то время как роботообразное встраивание в сетевую коммуникацию при отсутствии переживаний утраты реального общения, указывает на начавшийся процесс «самоампутации» духовности. И этот список типичных «синдромов», связанных с «ценностной болезнью» человека и общества, может быть продолжен.

Шелер много писал о нравственной стороне ценностности. В работе «Ресентимент в структуре моралей» он пишет о «прирожденном чувстве ценности собственного бытия», свойственном человеку $^{12}$. Именно это чувство само-ценности, собственного достоинства, полноты собственного бытия, к которому изначально стремится человек, «заряжает» его на ассимиляцию многообразия ценностей окружающего мира. В здоровом варианте это чувство - естественно, оно позволяет принимать чужие ценности и чужое превосходство без зависти, что делает мир для человека более наполненным и достойным любви. И, наоборот, в варианте нездоровом ощущение собственного достоинства основано только на оценочном сравнении собственной ценности и ценности окружающих. Постоянное внутреннее соперничество, «измерение других самим собой» и «самого себя другими» уводит человека от чистого восприятия ценностей, которые существуют в мире и которые он мог бы для себя открыть. В результате между таким человеком и миром ценностей возникает иллюзорная завеса: позитивные ценности, вызывающие зависть, обесцениваются и таким образом становятся для него недоступными. Да и сам диапазон его ценностного восприятия оказывается ограниченным только теми ценностями, которые становятся предметом сравнения, оценки. Ценностный этос индивидов, воспитанных в подобном духе, питает нынешний конкурентный социум, и наоборот, социальный этос эгоизма и соперничества создаёт жесткий каркас для неминуемого воспитания человека в утилитарно-конкурентном духе.

12 Шелер М. Ресентимент в структуре моралей. М.: Наука, 1999. (URL: http://krotov.info/libr_min/25_sh/el/er1.html). 
У эгоизма и конкурентности современного человека есть также и глубокие индивидуальные корни: ранняя фрустрация «прирожденного чувства ценности собственного бытия». Здесь мы не можем не затронуть психоаналитическую традицию рассмотрения сил, выступающих на арену индивидуальной истории индивида. Деструктивное действие внешних факторов, - в частности, ранних травм развития - порой подрывает сам фундамент, на котором могло бы сформироваться чувство индивида, что его бытие само по себе ценно. Так, в ряде концепций, более поздних по отношению к Шелеру, подчеркивается особое, почти главенствующее онтогенетическое значение базового чувства, которое формируется у человека при его первых встречах с миром: базовое доверие или недоверие (Э. Эриксон), онтологическая защищенность или незащищенность (Р. Лэинг) и др. Ранние фрустрации чувства ценности собственного бытия порождают экзистенциальную тревогу, впоследствии затрудняющую встречу человека с миром ценностей и неизменно толкающую его на «хитроумные» невротические «стратегии» поиска и подтверждения собственной ценности в этом мире. Следуя идее Шелера о стремлении человека к чувству само-ценности, мы можем описать драму невроза как изначально неудавшуюся и бесконечно повторяющуюся попытку человека сознательно или чаще бессознательно дотянуться до этого постоянно ускользающего чувства, используя широкий спектр доступных в социо-культурном арсенале стратегий поведения. Значительную их часть современный культурный этос декларирует как социальную норму. Цивилизация создала все условия для невротического восполнения человеком дефицита естественного чувства ценности самобытия, на любой «вкус и кошелек».

Одна из важных шелеровских работ посвящена феномену любви («Ordo amoris»). В наш век эгоизма дефицит любви очевиден. В аксиологическом понимании любовь - это не просто обнаружение ценности того, на что или на кого она направлена: это «приращение» данной ценности, раскрытие её потенциального совершенства. В любви человек движется вглубь мира ценностей, «от вершины - к более высокой вершине» ${ }^{13}$, и в конечном итоге - к божественному. Бог в антропологии Шелера - это вершина «пирамиды»

13 Шелер M. Ordo Amoris // Шелер М. Избранные произведения / Под. ред. А.В. Денежкина. М., 1994. С. 354. мира ценностей, «исток и цель одновременно» ${ }^{14}$. Философ придаёт главенствующее значение любви среди других духовных актов: она есть «побудительница познания и воления» и даже «мать самого духа и разума» ${ }^{15}$.

Мыслитель показывает огромную разницу между истинной, духовно переживаемой любовью и «простым сластолюбием». Двигаясь по пути истинной любви человек «устремляет взор дальше», чем «границы данного», всё больше углубляя переживание полноты бытия и ценности одного и того же объекта любви. А двигаясь по пути импульса простого влечения и ища наслаждения приятными объектами, человек быстро теряет импульс влечения, что толкает его к погоне за новыми и новыми объектами. И то и другое представляет собой бесконечный процесс. Но, как пишет Шелер, если бесконечный путь любви в его продвижении вглубь ценностей, от одной ценности к притягивающей другой, ко всё новым надеждам и предчувствиям, приводит к удовлетворению и нарастанию покоя (позитивно-ценностная безграничность любви), то непрекращающаяся погоня за наслаждениями тягостна и ощущается как «умножающееся беспокойство» ${ }^{16}$ (негативно-ценностная безграничность любви).

В контексте раскрытия понятия «любовь» через ценности Шелер говорит и о ненависти, понимая её как «превращенную любовь». Всякая ненависть, сколь бы ни была она связана с «антиценностью», с реакцией на неё, изначально проистекает из любви к ценности: только тогда возможна ненависть. Ненависть, пишет Шелер, «есть восстание нашего сердца и души против нарушения порядка любви» ${ }^{17}$. В частности, человек ненавидит, когда обнаруживает, что носитель негативной ценности занимает место носителя позитивной ценности. Эти важные обнаружения Шелера заставляет по-иному осмыслить многие жизненные феномены, когда любовь, пройдя сложный путь перверсии и напластований других эмоций, становится ненавистью. Присмотревшись, мы видим, что нена-

\footnotetext{
14 Там же. С. 356.

15 Чухина Л.А. Человек и его ценностный мир в феноменологической философии Макса Шелера // Шелер М. Избранные произведения / Под ред. А.В. Денежкина. М., 1994. С. 389.

16 Шелер M. Ordo Amoris // Шелер М. Избранные произведения / Под. ред. А.В. Денежкина. М., 1994. С. 355.

17 Там же. С. 369.
} 
висть, которой так переполнен наш сегодняшний социальный мир, часто выступает как «гримаса» адаптации индивида к социуму. В человеческой деятельности ненависть меняет вектор созидания (соответствующий любви) на вектор разрушения, в том числе и душевной самодеструкции. Такие перемены в человеке бывают трудно обратимы. Но подчас именно презумпция любви позволяет менять положение дел и усматривать в ненависти и тяге к разрушению отголоски противоположных чувств - и вывести их «на свет». Так, хороший психоаналитик помогает обнаружить пациенту в глубинах своего бессознательного фрустрированные чувства любви и дать им «место», что уже само по себе бывает достаточно, чтобы инициировать «обратный ход» ненависти. Любовь, в отличие от ненависти, сама, будучи переживаемой как благо, открывает для человека новые ценности и формирует смыслы. В отличие от ненависти, она является для человека самопополняемым источником жизненной энергии.

Рассуждая о патогенных ценностных процессах нынешней социокультурной реальности, мы неизбежно наталкиваемся на проблему различения ценностей по их антропологическому значению для человеческой природы, и здесь напрашивается условная граница между позитивными, или истинными ценностями, и негативными, или псевдоценностями. Этот важный для философской антропологии вопрос может звучать так: «всё ли ценность, что притягивает человека?» С философско-антропологической точки зрения, в открытии истинных ценностей человеческая природа обнаруживает и саморазворачивает себя. Проявляя изначально присущее ей свойство незавершенности и открытости бытию, она притягивает, осваивает и вновь обнаруживает всё новые его горизонты и потаённые слои. В этом и реализуется, по М. Шелеру, высшее назначение человека, его особость среди других существ, его открытость божественному, его особая роль в становлении бытия. Сталкиваясь же с реалиями нашего дня, мы видим всё многообразие ориентаций человека на псевдоценности, которые, на первый взгляд, по описанному Шелером «механизму» ведут себя как «все» ценности - притягивают, несут целе- и смыслообразующую функцию для человека. Эта «ценностная» мимикрия лежит в основе столь тотального сегодняшнего декаданса человеческой природы. В лучшем случае здесь речь идёт о кризисе, когда боль и страдания становятся для человека словно «сигналами» бы- тия, стимулирующими к мучительному, но продуктивному духовному поиску. В худшем - мы видим вырождение человеческой природы, замыкаемой на систему псевдоценностей, самокультивируемых нынешним социально-экономическим строем.

Не случайно в современном философском дискурсе набирает вес учение о благе - агатология, в отечественной литературе развиваемая В. Шохиным. Философ ставит особый акцент на дифференциации, с одной стороны, ценностей как сущностей относительных и, с другой стороны, благ, добродетелей как сущностей абсолютных, безусловных, незыблемых. В ходе историко-агатологического исследования автор приходит к выводу о несинонимичности данных понятий. Претерпев сложную эволюцию, понятие «ценность» изначально имела не этическое, а экономическое происхождение, и лишь впоследствии его семантическое ядро «обросло этическим слоями» ${ }^{18}$. Сегодня мы видим, как историческая эволюция самих ценностей являет нам не просто их деградацию, а подчас их инверсию, порождение ценностей - антиподов блага, разрушительных для человека: хаос вместо порядка, эгоизм вместо альтруизма.

Философская антропология сегодня чрезвычайно нуждается в ясном разделении названных понятий: с одной стороны, ценностей-благ как безусловных, абсолютных, внеисторических и, с другой стороны, культурно-исторических ценностных ориентиров (ценностных ориентаций) как относительных, условных, контекстуально зависимых. Если первые заложены в самой человеческой природе и открывают перед человеком действительно необъятную перспективу и новые горизонты «высшего проекта» бытия, то вторые, напротив, эту перспективу перед человеком сужают и ограничивают его существование тесным потолком социально-экономических реалий, редуцируя границы человеческого до микро-масштаба социальной функции. Аксиологическая трактовка антропологической модели человека, на наш взгляд, сегодня чрезвычайно актуальна. Она должна описывать ценности-блага, добродетели и святыни как подлинные конституэнты человека. Её должны интересовать широта и пополненность их ряда в структуре человеческой личности, объемность и многомерность индивидуального этоса человека. Ценности-суррогаты в данной трактовке должны

18 Шохин В. Агатология: современность и классика. М., 2014. C. 167. 
рассматриваться исключительно как деструкторы человеческой природы и антропофаги.

Мы живём в эпоху постмодерна, которая, казалось бы, выдвигает новый ценностный ряд на смену ценностям экономического выживания, доминировавшим в модернистский век. По исследованиям известного социолога Инглхарта, в условиях утвердившейся физической и экономической безопасности запросы человека смещаются на заботу о качестве жизни, свободу самовыражения, ценности плюрализма и личной автономии ${ }^{19}$. Однако при кажущейся гуманизации ценностных перемен глубинный аксиологический тренд в действительности зловещ. Исследователи постмодернизма связывают его скорее с бес-ценностностью: человек современной эпохи вообще теряет свою идентичность, обезличиваясь и распадаясь на множественные «я» ${ }^{20}$. Постмодернизм, проповедуя плюралистичность и безоценочность, в действительности фрагментирует реальность, лишая человека целостности и катастрофически усложняя ему возможности ценностной ориентации в окружающей действительности.

В условиях такой культурно-аксиологической трансформации конструирование антропологического эталона представляет собой непростую задачу. Однако, придерживаясь позиций, намеченных Шелером, с уверенностью можно сказать следующее: источник происходящих культурных коллизий - сама человеческая природа. Именно она, таящая в себе первоначальный порыв - источник влечений и побуждений, - несет в себе трудность и риск, предпосылку для ценностных «блужданий», для порабощения со стороны случайных, мнимых, суррогатных ценностей, легко замыкающих на себе природную энергию порыва, уводя её в сторону от осуществления проекта духа. И, пожалуй, главным ответом на вопрос о том, как не обессмыслить, не обесценить само бытие человека, может стать следующий: искать смысл и благо вопреки ходу прогресса, вопреки декадансу и культурному растлению. Этот смысл, это благо и эти истинные ценности сокрыты в глубинах бытия, и пробиться к ним возможно через душевный труд, мыслительное напряжение, через сопротивление реальности. Только через такие усилия возможен уход от обезличивания и обретение человеком личности, которое происходит именно через движение в глубину ценностного содержания бытия, через любовь к бытию, к Богу, как говорил Шелер. И только та структура индивидуальности может приравниваться установившейся, зрелой личности, в которой мы видим соединение природной энергии и духовного, аксиологического содержания. Только внутри этих полюсов и разворачиваются антропологические потенции, позволяющие говорить о целостности человека и о его будущем.

\section{Список литературы:}

1. Вотинцева Н. «Неценностный мир» постмодернизма (философско-аксиологический анализ) // Философия. Социология. Культурология. (Вестник Челябинского государственного университета). 2008. № 28 (129). С. 19-25.

2. Гуревич П.С. Современный век и его святыни // Педагогика и просвещение. 2012. № 2. С. 3-5.

3. Гуревич П.С. Современный век и его святыни (продолжение) // Педагогика и просвещение. 2012. № 3. С. 3-6.

4. Гуревич П.С. Современный век и его святыни (окончание) // Педагогика и просвещение. 2012. С. 3-5.

5. Инглхарт Р. Постмодерн: меняющиеся ценности и изменяющиеся общества // Полис (Политические исследования). 1997. № 4.

\footnotetext{
19 Инглхарт Р. Постмодерн: меняющиеся ценности и изменяющиеся общества // Полис (Политические исследования). 1997. № 4. (URL: http://www.sociology.mephi.ru/docs/polit/ html/ingl.htm).

20 Вотинцева Н. «Неценностный мир» постмодернизма (философско-аксиологический анализ) // Философия. Социология. Культурология. (Вестник Челябинского государственного университета). 2008. № 28 (129). С. 22-23.
} 
6. Маклюэн М., Фиоре К. Война и мир в глобальной деревне. М., 2012.

7. Малинкин А.Н. Философская социология Макса Шелера // Шелер М. Проблемы социологии знания. M., 2011.

8. Маркузе Г. Одномерный человек. М., 2011.

9. Чухина Л.А. Человек и его ценностный мир в феноменологической философии Макса Шелера // Шелер М. Избранные произведения / Под ред. А.В. Денежкина. М., 1994. С. 377-398.

10. Шелер M. Ordo Amoris // Шелер М. Избранные произведения / Под ред. А.В. Денежкина. М., 1994. C. 339-376.

11. Шелер М. Положение человека в космосе // Шелер М. Избранные произведения / Под ред. А.В. Денежкина. М., 1994. С. 129-194.

12. Шелер М. Ресентимент в структуре моралей. М.: Наука, 1999. (URL: http://krotov.info/libr_min/25_sh/ el/er1.html).

13. Шелер М. Формализм в этике и материальная этика ценностей // Шелер М. Избранные произведения / Под ред. А.В. Денежкина. М., 1994. С. 259-338.

14. Шохин В. Агатология: современность и классика. М., 2014.

15. Шохин В.К. Аксиология // Новая философская энциклопедия: В 4-х тт. / Под ред. В.С. Стёпина. М.: Мысль, 2001.

\section{References (transliteration):}

1. Votintseva N. «Netsennostnyi mir» postmodernizma (filosofsko-aksiologicheskii analiz) // Filosofiya. Sotsiologiya. Kul'turologiya. (Vestnik Chelyabinskogo gosudarstvennogo universiteta). 2008. № 28 (129). S. 19-25.

2. Gurevich P.S. Sovremennyi vek i ego svyatyni // Pedagogika i prosveshchenie. 2012. № 2. S. 3-5.

3. Gurevich P.S. Sovremennyi vek i ego svyatyni (prodolzhenie) // Pedagogika i prosveshchenie. 2012. № 3. S. 3-6.

4. Gurevich P.S. Covremennyi vek i ego svyatyni (okonchanie) // Pedagogika i prosveshchenie. 2012. № 4. S. 3-5.

5. Inglkhart R. Postmodern: menyayushchiesya tsennosti i izmenyayushchiesya obshchestva // Polis. (Politicheskie issledovaniya). 1997. № 4.

6. Maklyuen M., Fiore K. Voina i mir v global'noi derevne. M., 2012.

7. Malinkin A.N. Filosofskaya sotsiologiya Maksa Shelera // Sheler M. Problemy sotsiologii znaniya. M., 2011.

8. Markuze G. Odnomernyi chelovek. M., 2011.

9. Chukhina L.A. Chelovek i ego tsennostnyi mir v fenomenologicheskoi filosofii Maksa Shelera // Sheler M. Izbrannye proizvedeniya / Pod. red. A.V. Denezhkina. M., 1994. S. 377-398.

10. Sheler M. Ordo Amoris // Sheler M. Izbrannye proizvedeniya / Pod red. A.V. Denezhkina. M., 1994. S. 339-376.

11. Sheler M. Polozhenie cheloveka v kosmose // Sheler M. Izbrannye proizvedeniya / Pod red. A.V. Denezhkina. M., 1994. S. 129-194.

12. Sheler M. Resentiment v strukture moralei. M.: Nauka, 1999. (URL: http://krotov.info/libr_min/25_sh/el/ er1.html).

13. Sheler M. Formalizm v etike i material'naya etika tsennostei // Sheler M. Izbrannye proizvedeniya / Pod red. A.V. Denezhkina. M., 1994. S. 259-338.

14. Shokhin V. Agatologiya: sovremennost' i klassika. M., 2014.

15. Shokhin V.K. Aksiologiya // Novaya filosofskaya entsiklopediya: V 4-kh tt. / Pod red. V.S. Stepina. M.: Mysl', 2001. 